\section{QIJEI}

International Journal for Educational Integrity

\title{
Deregulation and control in international education: What happens in private training establishments in NZ?
}

\author{
Subhash Appanna \\ AIS St. Helens, NZ \\ subhasha@ais.ac.nz

\section{Sam Goundar} \\ Lecturer, Bay of Plenty Polytechnic, Tauranga, NZ. \\ Sam.Goundar@boppoly.ac.nz
}

Keywords: quality assurance, policy, practice, deregulation, control, international education

\begin{abstract}
The need for educational integrity intensified particularly after the effects of the public sector reform wave of the 1980s began to be felt by both education providers as well as governments. The prescribed toning down of government support, relaxation of regulatory 'impediments', centralisation of market competition and concomitant proliferation of private as well as public providers resulted in the need for a cost-profit focus in providers and a quality-integrity focus in policy frameworks. In the nonuniversity tertiary sector, numerous concerns and complaints continue to arise regarding 'profiteering' and sub-quality performance in the provision of education. By way of response, both providers as well as public policymakers have been involved in designing innovative frameworks aimed at ensuring integrity and quality in the provision of education in what is essentially a highly lucrative and competitive international market.
\end{abstract}

This paper critically analyses organisational responses to institutional requirements and expectations in the case of a Private Training Establishment (PTE) in New Zealand. Data for this research comes from a number of secondary sources, ongoing interviews with academics/administrators involved with organisations in the sector, and the notinconsiderable personal experiences of the two researchers. It concludes that deregulation, re-regulation and a reliance on the market as well as internal organisational controls, opens up the industry to serious compromises in terms of integrity of education. The findings should be of interest to stakeholders involved in the tertiary education sector.

\section{Introduction}

Government education policies became part of the broader public sector reform agenda as reconfiguration and re-rationalisation of the public sector gathered momentum after the 1980s. The rationale and prescriptions for this landmark, and highly ambitious, programme are encapsulated in the New Public Management (NPM) model - a "model for all seasons" (Hood, 1991). It is in tandem with this that the need for educational integrity intensified particularly after the effects of the reform wave of the 1980s began to be felt by both education providers as well as governments. The prescribed toning down of government support, relaxation of regulatory 'impediments', centralisation of

The International Journal for Educational Integrity is available online at:

http://www.ojs.unisa.edu.au/journals/index.php/lJEl/

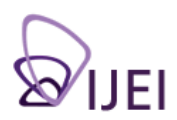


market competition and concomitant proliferation of private as well as public providers resulted in the need for a cost-profit focus in providers and a quality-integrity focus in policy frameworks. As the types of students, programmes and qualifications continue to expand in an unprecedented manner especially in the non-university tertiary sector, numerous concerns and complaints continue to arise regarding 'profiteering' and subquality performance in the provision of education. By way of response, both providers as well as public policymakers have been involved in designing innovative frameworks aimed at ensuring integrity and quality in the provision of education in what is essentially a highly lucrative and competitive international market. This paper critically analyses organisational responses to institutional requirements and expectations in the case of a Private Training Establishment (PTE) in New Zealand. Data for this case study based research comes from a number of secondary sources plus interviews with academics and administrators involved with the organisation scrutinised as well as other organisations in the sector. The research has also been helped by the notinconsiderable personal experiences of the two researchers. It concludes that deregulation, re-regulation and a reliance on the market as well as internal organisational controls, opens up the industry to serious compromises in terms of integrity of education. The findings should be of interest to stakeholders involved in the tertiary education sector.

\section{International education in New Zealand}

New Zealand's foray into international education dates back to the Colombo Plan of 1950. Reforms and liberalisation of the education sector commenced in 1984 with New Zealand's acclaimed public sector reform programme. It was around 1999/2000 that foreign student numbers jumped to 50,026 before hitting a record of 126,919 in 2002. The Ministry of Education website stated that "From 1999 to 2003, New Zealand's previously small international education sector, that is, in terms of enrolments of foreign fee-paying students, experienced rapid growth" (NZ Ministry of Education, 2011). In 2003 , there was a drop to 110,817 that was attributed to a decline in international enrolments in English language schools. This decline however, continued steadily to 88,557 in 2008. Increases were then seen in $2009(93,505)$ and $2010(99,880)$ (NZ Ministry of Education, 2011). It can be seen from Table 1 that a significant portion of students come from China which is the number one source of foreign students in New Zealand. The table also shows that Indian student numbers have shown remarkable increases after 2006 and pushed it to number three spot by 2010. It is significant to note that among the top four sources, India is the only one that has shown positive growth.

Table 1:

International students by origin

\begin{tabular}{|c|c|c|c|c|c|c|}
\hline & 2006 & 2007 & 2008 & 2009 & 2010 & $\begin{array}{l}\% \text { change, } \\
2006-2010\end{array}$ \\
\hline China & 33,649 & 25,216 & 21,080 & 21,327 & 21,258 & $-37 \%$ \\
\hline South Korea & 15,930 & 17,500 & 17,331 & 16,070 & 15,282 & $-4 \%$ \\
\hline Japan & 14,299 & 12,325 & 10,755 & 9,761 & 9,745 & $-32 \%$ \\
\hline India & 2,599 & 3,855 & 6,348 & 9,252 & 11,597 & $346 \%$ \\
\hline South East Asia & 7,216 & 7,660 & 7,662 & 8,535 & 9,328 & $29 \%$ \\
\hline Europe & 7,139 & 8,536 & 8,832 & 9,857 & 9,747 & $37 \%$ \\
\hline Latin America & 2,968 & 3,226 & 3,514 & 4,222 & 4,404 & $48 \%$ \\
\hline North America & 2,746 & 2,751 & 2,704 & 2,737 & 2,742 & $0 \%$ \\
\hline Middle East & 2,113 & 3,022 & 4,463 & 5,920 & 5,953 & $182 \%$ \\
\hline All other & 7,924 & 8,411 & 7,393 & 7,843 & 8,418 & $6 \%$ \\
\hline Totals & 96,583 & 92,502 & 90,082 & 95,524 & 98,474 & $2 \%$ \\
\hline
\end{tabular}

China includes the Hong Kong SAR. South East Asia is Thailand, Malaysia, Vietnam, Cambodia, Singapore, Philippines, and Indonesia. Europe is Germany, France, Spain, Switzerland, Czech Republic, United Kingdom, Russia, and Italy. Latin America is Brazil, Chile, Colombia and Mexico. North America is a total for the USA and Canada. Middle East is Saudi Arabia, Oman, and the United Arab Emirates. 
International education is New Zealand's fifth largest export industry generating some $\$ 2$ billion worth of income accounting for $1.13 \%$ of the country's GDP. This is forecast to rise to $\$ 3$ billion per year over the next five years (NZ Ministry of Education, 2009). International education also provides employment for about 32,000 citizens each year (Department of Labour, 2009). More importantly for the purposes of this paper, the increase in foreign student numbers after liberalisation of the education sector has continued to attract considerable entrepreneurial activity leading to a proliferation of private providers as well as innovative new offerings from existing institutions in the public sector. At present, New Zealand has 1,909 tertiary education providers: 688 PTEs, 20 Polytechnics, 37 Industry Training Organisations (ITOs), 9 universities and a number of more narrowly based institutions. The bulk of applications to the New Zealand Qualifications Authority (NZQA) for new course/programme approvals emanates from the largely profit-driven PTE segment. This paper analyses management practices and initiatives in a PTE in New Zealand within the NPM framework of reforms. PTEs are private organizations providing education/training (i.e. they are not state-owned). Their portfolio includes English language training as well as offerings towards academic certificates, diplomas and degrees at various levels. More importantly, PTEs are the fastest growing segment among education/ training providers in New Zealand.

\section{A philosophical re-orientation in public management}

Public sector reforms have been part of discourse on management in the public sector for the past two decades even though the management and organisation ideas contained in NPM can be traced back to earlier debates in public administration (Savoie, 1995, pp. 119-120). Pointed concerns had been raised much earlier by Arrow (1963); this was followed later by Niskanen (1971). By 1990, when enough coherent features had emerged to resemble a 'model' for management, it was evident that the means and ends of management in the public sector were slated for revolutionary change. Up till then, administration (and management) in the public sector had been characterised to various extents by features of the bureaucratic model. Weber's rational-legal model of organisation (commonly known as bureaucracy) was considered to be technically superior to any other form at the time of its conception because it was underpinned by rationality and legality. Kamenka (1989, p.157) says:

"bureaucracy" means a centrally directed, systematically organized and hierarchically structured staff devoted to the regular, routine and efficient carrying out of large-scale administrative tasks according to policies.

This type of social organisation was supposed to be characterised by centrally commanded, devoted, specialised and competent staff, closely following rules and procedures to arrive at consistent impersonal decisions efficiently and without controversy. Bureaucracy as a concept thus holds within it, logical and practical relationships, mutually supportive characteristics, principles, attitudes and traditions that struggle to perpetuate the ideal type against internal as well as external changes, stresses and contradictions - this is where the bulk of its criticisms focus. Its offshoot, the traditional public administration model, was found to be too inward-looking, restrictive and non-responsive to customers as well as changes in the environment. Post-bureaucratic attempts thus focused on promoting the restructuring of rigid frameworks, innovation, cost cutting techniques and directing priorities to customer demand and quality (Ledema, 2003; Knights \& Willmott, 2004) - this became the rationale for a new model to replace traditional public administration.

The NPM model thus emerged through attempts to address the more obvious and disruptive shortcomings of traditional public administration. In a departure from reliance on rules, regulations and procedures within a hierarchical structure, it 
assumes that the market is preferable to government as an intermediary for resource allocation, utilisation and public service delivery "since it involves transactions that are voluntary, lateral and decentralised, in contrast to the compulsory, hierarchical and centralized activities of government" (Beetham, 1987, p. 33). From this perspective NPM's promise has two points of focus: removal of the constraints of bureaucracy, and freedom to make decisions in a more enterprising manner with the focus on efficiency, effectiveness and economy.

\section{Devolution and controls}

NPM-informed reforms attempt to remove institutional/government controls in order to free up and encourage the entrepreneurial spirit, and replace it with organisationdesigned systems, complemented with an appropriate values system, that replaces the macro-controls that have either been relaxed or removed. OECD describes NPM as a replacement of the traditional process/rules driven management paradigm by one that attempts to combine modern private sector type management practices with the logic of economics, while still retaining the core public service values. This raises the question of compatibility between public service values and private sector management practices. Others consider NPM to be too radical and potentially hazardous because of the insurmountable difficulties involved in accommodating it within the value and standards framework of traditional public administration. Moe (1984) sees NPM as having a value framework that is clearly different from that of traditional public administration. Beetham adds another dimension by saying that, "a necessary condition for the market to operate ... is a framework of legal compulsion, to guarantee the security of person and property, the integrity of contracts and the soundness of the monetary system" $(1987$, p. 27). These are essential parts of effective governance structures that are crucial for good governance in both NPM as well as any other attempts to introduce market discipline into the workings of government organisations. The challenge is to determine to what extent macro controls can be relaxed/removed without compromising quality and standards in the education sector. The search for answers to this is ongoing - the following sections attempt to raise issues around this question by outlining and discussing real-life examples from a PTE in New Zealand.

\section{Conception of PTEs}

As mentioned earlier NPM-informed reforms attempt to encourage and facilitate business enterprise in areas previously operating within the public bureaucracy by removing institutional/government controls. This is linked to the rationale of small government and private sector-led growth where regulation and control is seen as an impediment to the entrepreneurial spirit. Interest in the PTE sector is thus led by private capital and mainly driven by the profit motive. Process and systems requirements prescribed by NZQA are 'acceptably' met after a prolonged period of 'negotiations' and 'firm refusals'. There is no guarantee however, that these systems would be adhered to in practice as too often market popularity in the name of customer-focus tends to override integrity and standards concerns. Furthermore, the values systems that develop in these institutions are far removed from the public ethos assumed in NPM. That ethos comes from a prolonged history of operating in the public domain with tightly prescribed expectations. Hummel (1987) says that beneath the formal structures in a public sector organisation is a supporting "psychological structure of bureaucracy". The public ethos contained there operates as an internal psychological control device somewhat like organisational culture in private-sector organisations. In the civil servant, it operates via concern for public interest, belief in the value of collective provision of essential services, due regard to law and legal rights, and conscientious performance of duty. This assertion of public administration obviously downplays the strong and disruptive influence that pecuniary self-interest can have on the workings of the individual as well as the institution. In the case of the PTE in question, the personnel involved almost invariably do not have a 
shared past, nor do they have the theoretically-assumed 'public' background that would help transmit the public ethos into the private-style organisation. With the private company status and resultant private-sector objectives, the expected public ethos-type control is exchanged for a customer-focused, profit-driven orientation that almost by definition requires leeway in decision-making. This creates an 'ends' focus that tends to downplay the 'means' that have traditionally been considered indispensable in the education sector given its nature, role and wider societal significance.

\section{Administrators and academic staff}

NPM is based on the tenets of Freedom to Choose and Freedom to Manage. Freedom to choose arises from the new administrative reform doctrines built on ideas of contestability, user choice, transparency, and incentive structures. These come from the new institutional economics movement, which has its basis in Public Choice, Agency Theory, Transaction Cost Theory and Theories of Bureaucracy. On the other hand, freedom to manage entails business-type managerialism in the public sector in line with the international scientific management movement (Merkle, 1980). Administrative reform doctrines arising from this movement include the portability of professional management expertise (Martin, 1983), the paramountcy of professional over technical expertise, the need for high discretionary powers (free to manage) in management, and its centrality and indispensability for better organisational performance through the development of better organisational cultures (Peters \& Waterman, 1982), as well as active measurement and adjustment of organisational output. Thus NPM prescribes that the best people need to be hired for identified positions within the organisation, the best incentives must be allocated to them, and they must be provided with the right resources and discretionary decision space only then would the expected outcomes be realised and justify professional performance appraisal.

In the case of the PTE under study, none of the personnel were hired as the 'best' for the position as prescribed by NPM. Most had applications to other more mainstream providers rejected; many admitted that they were grateful to be employed; and many continued to apply for jobs elsewhere - that is the nature of the market. On the other hand, a large number of academic staff were part-timers who held positions elsewhere. Part-time staff simply teach courses at pre-set times and have minimal involvement with the institution. They are also particularly conscious about holding onto their jobs as a source of extra income - this is a particular concern among the predominant immigrant staff who almost invariably have mortgages to service. Furthermore, the cost-focused remuneration packages offered do not attract the type of personnel envisaged by NPM. Thus the organisation has a more-or-less captive administrative and academic staff base that has power implications in terms of what the staff can and cannot do. A number of senior technical-administrative positions established on the insistence of NZQA have, over time, been relegated to ancillary status. These have good enough remuneration packages to attract appropriate people; they also have the highest turnover rates as individuals get frustrated with unclear expectations, inadequate appropriation of powers to match the responsibilities involved, unnecessary and inordinate meddling into decision-making by immediate supervisors, etc. Luckily, these personnel (unlike most staff) have been able to locate employment elsewhere. Many academic staff have also quietly expressed frustration at the fact that it is personally hazardous to fail students. Being aware of this, students have been quick to lodge complaints against staff knowing that they would be supported by top management who are also part owners or are on high enough salaries with no real parallel options of finding employment elsewhere at this stage in their careers. More on student expectations and input is presented later. 


\section{Centralized decision-making}

As mentioned earlier NPM centralises the portability of professional management expertise (Martin, 1983), the paramountcy of professional over technical expertise and the need for high discretionary powers (free to manage) in management. This is particularly important in the education sector as concerns, other than profits only, are very much part of expected outcomes. It is in recognition of this that NZQA has made it a non-negotiable requirement that personnel with acceptable academic backgrounds be part of the management team in education providers in New Zealand. Without this, applications for registration are rejected as the bulk of the interest has almost invariably been entrepreneurial especially in the PTE segment. In the PTE studied here, top management comprises managers and shareholders, the bulk of whom do not have an established academic and/or extensive academic administration background. Decisions however are centralised not only among this group, but among the main shareholders. In one case, a mid-level administrative staff was cited for disciplinary action for setting and administering an academic examination without involvement by the lecturer concerned. There were also rumours of her selling exemplary assignments from previous students to interested new students among a slate of other unethical-looking issues. The disciplinary committee, chaired by a non-shareholder member of top management, decided to terminate her employment. The very next day, she was miraculously transferred laterally with no questions asked. Quiet conversations revealed that this was due to a directive from the 'top'. Further discussions revealed that it was common for students who had failed courses to make remonstrations to the 'top' with subsequent phone calls being made to programme heads to 'investigate' the issue. The unspoken message in these requests appears to have been to find out 'how the student can pass'. One senior manager clearly stated in an email that: "as a private business we need to attract and graduate students". This obvious emphasis on profits and the absolutely centralised decision-making structure, not only defies the prescriptions of NPM, it dilutes/removes the all-important academic concern in senior decision-making in what is essentially an academic institution that was conceived as a business entity. The problem is further exacerbated when academic managers either vacillate in decision-making, do not allow adequate standardisation of processes to help set precedents or display lack of consistency in decision-making. The question that arises is: why is this being developed and allowed to become part of organisational culture?

\section{Policies and processes}

Despite the emphasis of reforms to deregulate, the wider institutional requirements for PTEs have been tightened after the initial 'free' focus; these requirements are clearly spelt out on the NZQA website. Policies, processes, stakeholder involvement, etc., are closely scrutinised before approvals are granted. Problems arise however, in the assumptions guiding these stipulations as well as the manner in which these are actioned by the PTE. As an example, student input through formal evaluations, etc., is required by NZQA. In practice, this is used to pressure academic staff to ensure that students do not fail their courses. On the one hand, it encourages staff input and commitment; on the other, it motivates staff to overlook shortcomings and pass students even if they do not deserve to pass. This also infuses a popularity element in the manner in which staff enforce rules and standards. In a number of cases, staff have desperately appealed to students either directly or indirectly to make positive comments or avoid making negative comments on evaluation forms. As an example of lax enforcement of standards, students taking an 11th course were repeatedly found not to know how to reference sources used in assignments. During discussions with the researchers, staff just shook their heads and advised that it would not help to enforce that requirement even though it should be taken for granted that students at degree level would know the importance of citing sources. In an insidious extension of the same pressure on staff, the performance appraisal process is not only carried out 
in a self-serving manner, but gives inordinate importance to student complaints. In one case involving 18 students, negative comments by two were taken to totally eradicate positive comments by the rest. This appears to be standard practice and remonstrations have fallen on deaf ears according to other staff interviewed. The assumption behind the NZQA requirements for student evaluation and the manner in which management entertains and uses student feedback, appears to be that students operate in their self-interest and that they want to learn and acquire the best value for their money.

Unfortunately this assumption is flawed when one considers student attitudes towards class attendance, enforcement of rules and standards, expectations from the institution, etc. It is not uncommon for students to demand long breaks during classes as well as early finish. It is also not uncommon for students to ask for multiple-choice questions in tests and exams or demand for open-book tests. In a number of cases, students who failed argued with their lecturers later saying, "how come I fail when I pay?". Complaints lodged with top management by students have led to unwritten reprimands with a clear understanding that the institution considers student failure as the responsibility of the lecturer concerned. In one case, a lecturer who joined from a polytechnic attempted to enforce standards that he was used to. A group of students complained to a junior administrator who advised them on an insidious route to 'get back' at the lecturer. As the course proceeded, that group of students became uncooperative and reactive; when it finished, not surprisingly all had failed. A formal complaint was then lodged with the Head of Program who promptly fired the staff and overturned all the results by involving another staff who was hired as replacement. This person had been waiting for a 'gap' to join the institution and was eager to prove his worth. The manner in which the indignant lecturer was fired would have been considered 'shocking' under normal circumstances; he was never informed about his dismissal, arrived to teach his next class and found his replacement already at work delivering a lecture. This would seem to indicate an interesting management attitude towards enforcement of rules and standards as well as towards wider established HR/ IR protocols.

In another case, a student began to submit pieces of a major assignment that exhibited a level of English that did not match her ability to speak the language. Her lecturer became suspicious and summoned her for an interview where he confirmed that she simply could not be the one who wrote that piece of the assignment. Further investigations revealed that she had actually hired a ghostwriter for a fee. In one message to the student, the ghostwriter wrote:

Your whole report has been completed. Please deposit rest of study fee to my account. It is $\$ 1700$. ANZ XXXXX. After you deposit, let me know. I will sent final report to your email.

A fictitious student was then created by the lecturer to verify this; he emailed the same writer for assistance and promptly got the response:

Thank you for your email. I can help your work. I can also choose the topic for you. Call me on XXXX.

The staff member concerned then reported this to his immediate superior in the process who prepared a report, complete with recommendations, for the senior manager concerned. Almost two months later he raised the issue with the senior manager who said that he had just made a decision two working days back - this was later confirmed not to be entirely accurate as a decision had been conveyed to relevant personnel three weeks after the initial report had been made. The senior manager further stated that (as recommended) the particulars of the case had been handed over to police to deal with the ghostwriter as deemed fit. Staff of the 
institution, however revealed that no police had been seen on the premises.

Moreover, neither of the staff who were involved with the original investigations in the case were contacted by police. This could therefore, have been another lie connected with the case. Moreover, why was there a need to engage in this subterfuge? The penalty for the student was: two de-merit points, a leave (not suspension) of four months, and the requirement that all the work done for the assignment would be scrapped and the student would need to submit a brand-new assignment. This would not appear to be in line with established procedures and expectations in academia; thus there is a clear divide between policy and practice that is driven by self-interest rather than the wider concerns of society as would have been expected of an academic provider regardless of whether it is a private or public institution.

\section{Discussion}

It is not surprising that deregulation and the removal of restrictions in the education sector in New Zealand has created significant business opportunities for private provision of education - this was both expected and encouraged. According to NZQA officials, interest in starting up new schools or changing/adding programmes of study continues to be robust. Concerns however, continue to be voiced about rogue institutions that have a short-term profit focus. What is more disturbing is that numerous complaints continue to be raised about institutions operating as 'massproduction plants' - these complaints have largely been aimed at PTEs. Thus there is a dilemma on the issue of how and/or to what extent PTEs could and should be controlled in New Zealand so that an academic qualification obtained from a PTE should have roughly the same 'weight' as that obtained from a polytechnic or a university.

It is virtually accepted now that this dilemma between devolution and control stems from inconsistencies found within the NPM model itself. A close scrutiny of the literature on NPM does not clearly exhibit uniformity on exactly what it constitutes, but a number of ideas and initiatives appear to characterise the model (Hood, 1994; Pollitt, 1995; Boston, Martin, Pallot, \& Walsh, 1996). On the other hand, there appears to be general unanimity on NPM's fundamental objectives of creating an innovative, flexible, problem-solving, and more entrepreneurial culture that is better adapted and more adaptable to a changing environment (Barzely, 1992; Kettl, 1997; Rosenbloom, 1998). NPM therefore, is weak on specifying the means to achieving these highly desirable ends. It is this, combined with the profit-motive inherent in the self-interest assumption, that has led to the types of behaviours discussed in the case of PTEs. Grey (2005) says that while the post-bureaucratic model has been considered adequate, its potential influence on formal organisational structures has been linked to heightened risk and slackening of control. There is thus little arguing that some sort of re-regulation or strengthening of existing frameworks is warranted in the education sector.

Arellano-Gault (2000, p. 400) says that "in the absence of robust institutions for administrative control and oversight (the) use of NPM (as a top-down reform strategy) faces [...] basic dangers". Christensen and Laegreid (2001, p. 104) add that "the price for more devolution, flexibility, autonomy and discretionary power for managers (in NPM) is a more formal, rigid, hierarchical control system that makes extensive use of contracts." However, for effectively evaluating the performance of both the manager/s and the PTE, it is important to have explicit standards and measures of performance because NPM links performance directly to merit-based rewards and penalties (Hood, 1991; Boston, et.al., 1996). Thus clear mutually agreed-upon objectives and timeframes need to be set for effective control as necessitated by the accountability provisions of the model. NPM attempts to replace detailed control by a more competent central capacity for control. This competence is supposed to be made possible through the contractual setting of specific numerical targets and objectives that facilitate better monitoring and measurement of results (Christensen \& Laegreid, 
2001, p. 104). Setting clear objectives in the public sector however, is a task fraught with contradictions in itself. This should be a prioritised challenge for regulatory authorities.

The emphasis on external audits and reviews is a clear innovative attempt to externally manage and control PTEs at the expense of more traditional internal control mechanisms (Power, 1994). This renewed recognition of the need for controls in the aftermath of restructuring using NPM moves focus to the more widespread and embracing concept of governance structures. The dilemma thus resides first and therefore, needs to be solved first at the political level. This is again a task fraught with contradictory considerations. Regulatory authorities, in the meantime, need to identify loopholes that are already being or could be abused by PTEs, amplify their presence within the general psyche of PTEs and improve the overall quality of vigilance that they are tasked with.

\section{References}

Arellano-Gault, D. (2000). Challenges for the new public management: Organizational culture and the administrative modernization program in Mexico City (19951997). American Review of Public Administration, 30(4).

Arrow, K. J. (1963). Social choice and individual values. New York: Wiley.

Barzely, M. (1992). Breaking through bureaucracy: A new vision for managing in government. Berkeley: University of California Press.

Beetham, D. (1987). Bureaucracy. Milton Keynes: Open University Press.

Boston, J., Martin, J., Pallot, J., \& Walsh, P. (1996). Public management. The New Zealand model. Auckland: Oxford University Press.

Christensen, T., \& Laegreid, P. (Eds.). (2001). New public management. The transformation of ideas and practice. Aldershot: Ashgate Publishing Co.

Department of Labour (2009). The New Zealand knowledge economy - at a glance. Retrieved February 15, 2010, from http://www.dol.govt.nz/PDFs/kesummary.pdf

Grey, C. (2005). A very short, fairly interesting and reasonably cheap book about studying organisations. London: Sage Publications LTD.

Hood, C. (1991). A public management for all seasons. Public Administration, 69(1), 3 $-19$.

Hood, C. (1994). Explaining economic policy reversals. Buckingham: Open University Press.

Hummel, R. P. (1987). The bureaucratic experience (3rd ed.). NY: St. Martin's.

Kamenka, E. (1989). Bureaucracy. New perspectives on the past. Cambridge, MA: Basil Blackwell.

Kettl, D. F. (1997). The global revolution in public management: Driving themes, missing links. Journal of Policy Analysis and Management, 16(3), 446-462.

Knights, D., \& Willmott, H. (2004). Introducing organizational behaviour and management. London: Thomson Learning.

Ledema, R. (2003). Discourses of post-bureaucratic organization. USA: John Benjamins Publishing Company.

Martin, S. (1983). Managing without managers. Beverly Hills: Sage.

Merkle, J. (1980). Management and ideology: The legacy of the international scientific management movement. Berkeley: California University Press.

Moe, T. M. (1984). The new economics of organization. American Journal of Political Science, 28(4), 739-777.

Niskanen, W. A. Jr. (1971). Bureaucracy and representative government. Chicago: Aldine Publishing Co.

NZ Ministry of Education (2009). International student enrolments in New Zealand 2002-2008. Wellington: International Division, Ministry of Education. 
NZ Ministry of Education (2011). Prospects for international student enrolments in New Zealand: Profiles of 13 source countries. Wellington: International Division, Ministry of Education.

Peters, T., \& Waterman, R. H. Jr. (1982). In search of excellence. NY: Harper \& Row Publishers.

Pollitt, C. (1995). Justification by works or by faith? Evaluating the New Public Management. Evaluation, 1(2).

Power, M. (1994). The audit explosion. London: Demos.

Rosenbloom, D. (1998). Public administration: Understanding management, politics, and law in the public sector (4th ed.). New York: McGraw-Hill Companies.

Savoie, D. J. (1995). What is wrong with the new public management? Canadian Public Administration, 38, 119-120.

\section{About the authors}

Subhash Appanna is a PhD candidate at Swinburne University (Melbourne, Australia), an adjunct lecturer at the Fiji National University (FNU, Fiji) and the MBA research coordinator at AIS St. Helens in Auckland. Prior to this, Subhash held a number of senior teaching and administrative positions within the Faculty of Business and Economics at the University of the South Pacific where his contributions to distance learning include his writing of two course packages: Introduction to Management (1998) and Operations Management (2000). A respected researcher and political commentator, Subhash has presented a number of papers at noted international conferences. He is attached as a reviewer to a number of conference circuits as well as journals. His research interests and publications span the management, economics, governance, indigenous business, and education spectrum.

Sam Goundar is an academic and researcher at the Bay of Plenty Polytechnic in New Zealand. He has taught at the University of the South Pacific and the University of Fiji for a number of years. He has also worked in the IT industry as an Advisor and Consultant managing IT projects and the IT function of government ministries in Fiji. Apart from teaching IT courses, he has also taught management courses for a number of years. He started on his PhD research at The University of the South Pacific in 2007 focusing on e-Government in Fiji and has continued working on his $\mathrm{PhD}$ now focusing on the same with Cloud Computing. His research papers have been published in IEEE and AIS conference proceedings. His current research is focused on using mobile devices in education.

An earlier version of this paper was originally published in the refereed proceedings of the $5^{\text {th }}$ Asia Pacific Conference on Educational Integrity: Culture and values. The University of Western Australia, 26-28 September: http://www.apcei.catl.uwa.edu.au/ procs 